\title{
Molecular signatures of chronic myeloid leukemia stem cells
}

Yaoyu Chen ${ }^{1}$ and Shaoguang $\mathrm{Li}^{2,3^{*}}$

\begin{abstract}
$B C R-A B L$ tyrosine kinase inhibitors (TKIs) are effective in controlling Philadelphia-positive $\left(\mathrm{Ph}^{+}\right)$chronic myeloid leukemia $(C M L)$ are unlikely to cure the disease because TKIs are unable to eradicate leukemia stem cells (LSCS) responsible for the disease relapse even after tyrosine kinase inhibition. In addition, the TKI resistance of LSCs is not associated with the $B C R-A B L$ kinase domain mutations. These observations indicate that TKI-insensitive LSCS and TKI-sensitive leukemic progenitor cells are biologically different, which leads us to believe that LSCs and more differentiated leukemic cells have different genetic mechanisms. Further study of LSCs to identify the novel gene signatures and mechanisms that control the function and molecular phenotype of LSCs is critical. In this mini-review, we will discuss our current understanding of the biology of LSCs and novel genes that could serve as a molecular signature of LSCs in CML. These novel genes could also serve as potential targets for eradicating LSCs in CML.
\end{abstract}

Keywords: BCR-ABL, Leukemic stem cells, CML, Biomarker, Hematopoietic stem cells, Cancer stem cells

\section{Introduction}

Human Philadelphia chromosome-positive $\left(\mathrm{Ph}^{+}\right)$leukemia induced by the $B C R-A B L$ oncogene is the most common myeloproliferative disorder known as chronic myeloid leukemia (CML). CML often starts with a chronic phase, which is characterized by granulocytosis and splenomegaly. The disease can progress to acute leukemia. CML starts with a chronic phase and progresses to a more acute terminal phase called "blast crisis" resulting in development of acute myeloid or acute B-lymphoid leukemia, which is characterized by granulocytosis and splenomegaly. More than ten years ago, a BCR-ABL kinase inhibitor called imatinib mesylate (Gleevec/Glivec, formerly STI571; Novartis) was approved by FDA for treating CML patients $[1,2]$. The rate of complete cytogenetic response among patients receiving imatinib was $87 \%$ after 5 years of treatment [3]. Although it effectively inhibits the BCR-ABL kinase activity and improves the survival of CML patients, imatinib does not appear to lead to a cure of the disease, because patients in complete cytogenetic remission after imatinib treatment still contain $B C R-A B L$-expressing leukemia cells.

\footnotetext{
* Correspondence: shaoguang.li@umassmed.edu

${ }^{2}$ Department of Medicine, Division of Hematology/Oncology, University of

Massachusetts Medical School, 364 Plantation Street, Worcester, MA 01605, USA ${ }^{3}$ Department of Medicine, University of Massachusetts Medical School, 364

Plantation Street, Worcester, MA 01605, USA

Full list of author information is available at the end of the article
}

One explanation is that survival of those primitive CML cells were not dependent on BCR-ABL kinase activity so that therapies that biochemically target BCR-ABL could not eliminate CML stem cells $[4,5]$. Those CML patients will most likely be required to take the drug for the rest of their lives [6]. The resistance of LSCs to kinase inhibitors suggests that $B C R-A B L$ may activate some unique and unknown molecular signaling pathways through both kinase-dependent and kinase-independent mechanisms in LSCs [7].

$B C R$ - $A B L$-expressing hematopoietic stem cells function as LSCs of CML and are resistant to BCR-ABL kinase inhibitors Cancer stem cells (CSCs), including LSCs in CML, constitute a subpopulation of malignant cells capable of self-renewal and differentiation [8-12]. Recently, CSCs have been defined by their ability to repeatedly generate a continuously growing tumor [13]. Weissman and colleagues proposed that a candidate CSC population should exhibit the following properties: 1) The unique ability to engraft; 2) The ability to replicate the tumor of origin both morphologically and immunophenotypically in xenografts; and 3) The ability to be serially transplanted [13].

CML occurs because of clonal expansion of $B C R-A B L-$ expressing hematopoietic stem cells. In CML patients, a $B C R-A B L$ containing leukemic clone typically produces 
the myeloid lineage cells and B-lymphoid cells. LSCs in CML have some characteristics of normal hematopoietic stem cells. The $B C R-A B L$ retroviral bone marrow transduction/transplantation mouse model has been widely used to establish a more efficient CML mouse model for studying the biology of LSCs [14]. By using the CML mouse model, $B C R-A B L$-expressing Lin $^{-} \mathrm{c}-\mathrm{Kit}^{+} \mathrm{Sca}-1^{+}$ cells were shown to function as LSCs in chronic phase CML [15].

BCR-ABL kinase inhibitors: imatinib, dasatinib and nilotinib were developed to treat CML and imatinib now serves as the frontline therapy for the patients with chronic phase CML [16]. Even though it can control CML development effectively, imatinib does not appear to cure the disease. One possible reason is that LSCs are insensitive to kinase inhibitors. Imatinib kills almost all dividing cells; however, a significant population of viable CD $34^{+}$cells are unaffected by the treatment and are leukemic in nature [5]. The fact that imatinib could not target the quiescent $B C R-A B L$-expressing LSCs made it apparent that imatinib treatment alone could not cure CML $[5,17]$. Human CML stem cells do not depend on BCR-ABL kinase activity for survival and are thus not eliminated by imatinib therapy. Imatinib inhibited BCRABL kinase activity to the same degree in all stem $\left(\mathrm{CD} 34^{+}\right.$ $\left.\mathrm{CD} 38^{-}, \mathrm{CD} 133^{+}\right)$and progenitor $\left(\mathrm{CD} 34^{+} \mathrm{CD} 38^{+}\right)$cells and in quiescent and cycling progenitors from newly diagnosed CML patients. Although short-term in vitro imatinib treatment reduced the expansion of CML stem/progenitors, cytokine support permitted growth and survival in the absence of BCR-ABL kinase activity that was comparable to that of normal stem/progenitor counterparts. Primitive human CML cells are insensitive to imatinib treatment and therapies that biochemically target BCR-ABL kinase activity will not eliminate CML stem cells [18]. The minimal effect of BCR-ABL kinase inhibitor on LSCs was also observed in the CML mouse model [15]. Neither imatinib nor dasatinib show a complete eradication of $B C R-A B L-$ expressing HSCs.

\section{Identification of novel gene signatures of LSCs in CML}

Recently, several novel gene signatures in LSCs are identified to monitor the function and activity of LSCs after CML patients receive BCR-ABL kinase inhibitors treatment or other novel therapies (Table 1 and Figure 1).

\section{Cell metabolism regulators}

Arachidonate 5-lipoxygenase (Alox5) gene encoding arachidonate 5-lipoxygenase (5-LO) is involved in numerous physiological and pathological processes, including oxidative stress response, inflammation and cancer [19]. 5-LO is responsible for producing leukotrienes, such as LTB4, LTC4 and LTD4, a group of inflammatory substances that cause human asthma [19]. Altered
Table 1 List of novel gene signatures in LSCs

\begin{tabular}{lll}
\hline Gene name & Chr & Gene function \\
\hline$\beta$-catenin & Chr3 & Cadherin-associated protein \\
\hline Smo & Chr7 & Smoothened, frizzled family receptor \\
\hline Alox5 & Chr10 & Arachidonate 5-lipoxygenase \\
\hline Scd1 & Chr19 & Stearoly-coenzyne A desaturase 1 \\
\hline Src kinase & Chr20 & Kinase \\
\hline Selp & Chr1 & Granule membrane protein 140 kDa, antigen CD62 \\
\hline CD44 & Chr11 & Antigen \\
\hline Msr1 & Chr8 & Macrophage scavenger receptor 1 \\
\hline Foxo3a & Chr6 & Forkhead box O3 \\
\hline Hif1a & Chr14 & Hypoxia inducible factor 1 \\
\hline Pten & Chr10 & Prosphatase and tensin homolog \\
\hline Bc16 & Chr3 & B cell leukemia/lymkemia 6 \\
\hline PML & Chr15 & Promyelocytic leukemia \\
\hline PP2A & Chr19 & Protein phosphatase 2A \\
\hline
\end{tabular}

arachidonate metabolism by leukocytes and platelets was reported in association with myeloproliferative disorders almost 30 years ago. Recently, Alox 5 was shown to be a critical regulator for LSCs in CML. Alox5 is significantly upregulated by BCR-ABL kinase and this upregulation does not depend on its kinase activity. In the absence of Alox5, $B C R-A B L$ fails to induce CML in mice [20]. This Alox 5 deficiency caused impairment of the function of LSCs but not normal hematopoietic stem cells (HSCs) through affecting differentiation, cell division and survival of long-term LSCs, consequently causing a depletion of LSCs and a failure of CML development. Similar results were obtained when mice with CML were treated with a 5-LO inhibitor. Human CML microarray studies also showed that Alox5 is differentially expressed in CD34 ${ }^{+}$CML cells, suggesting a role of Alox5 in human CML stem cells. This data suggests that Alox5 and its pathway plays an important role in self-renewal and differentiation of LSCs and could be potential biomarkers for monitoring the activity of LSCs in patients [20].

Stearoyl-CoA desaturase $\mathbf{1}$ (Scd1) is an endoplasmic reticulum enzyme, belonging to a family of $\Delta 9$-fatty acid desaturase isoforms. Scd1 catalyzes the biosynthesis of monounsaturated fatty acids from saturated fatty acids, which are the most abundant fatty acids present in mammalian organisms [21]. The expression of the Scd1 gene is downregulated in LSCs and Scd1 plays a tumor-suppressive role in LSCs with no effect on the function of normal HSCs. Deletion of Scd1 causes acceleration of CML development and conversely overexpression of Scd1 delays CML development. In addition, Pten, p53, and $\mathrm{Bcl} 2$ are regulated by Scd1 in LSCs. Furthermore, the induction of Scd1 expression by a PPARY agonist suppresses LSCs and delays CML development [22]. 


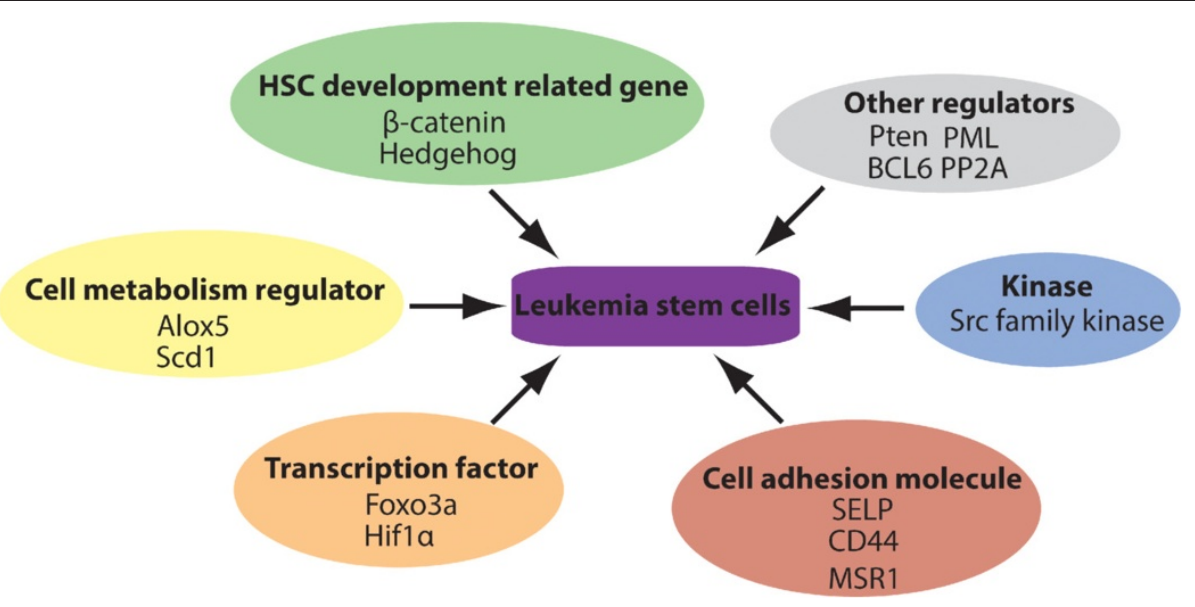

Figure 1 Different novel gene signatures regulate the function of LSCs.

\section{Genes related to normal development of hematopoietic stem cells (HSCS)}

$\boldsymbol{\beta}$-catenin is a key factor in HSC development, and is activated by Wnt ligand binding to the receptor. Its stability after activation is highly regulated by a destruction complex involving the tumor suppressor Adenomatous Polyposis Coli (APC), the scaffolding protein that binds newly synthesized $\beta$-catenin. Two kinases Choline Kinase (CKI) and Glycogen Synthase Kinase $3 \beta$ (GSK3 $\beta$ ), phosphorylate Ser and Thr residues in the amino terminus of $\beta$-catenin [23]. In CML patients undergoing blast crisis, $\beta$-catenin is activated in myeloid progenitors and the activated $\beta$-catenin translocates to the nucleus [24]. In CML mouse model, deficient of $\beta$-catenin causes a reduced ability of $B C R-A B L$ to support long-term renewal of LSCs, as shown in the serial replating and transplantation assays [25]. The inhibitory role of $\beta$-catenin in LSCs is associated with the decreased levels of p-Stat $5 \alpha$ and associated with the overexpression of $A B C B 1$, which gives rise to the multidrug resistance (MDR) phenomenon [25]. Antagonism of this pathway also led to impaired NFAT activity, decreased cytokine production, and enhanced sensitivity to BCR-ABL inhibition [26]. It is also known that increased exogenous Wnt-mediated $\beta$-catenin signaling played an important role in mesenchymal stromal cells -mediated protection of CML progenitors from tyrosine kinase inhibitor treatment [27]. Wnt/ $\beta$-catenin signaling pathway was also shown to be required for the development of LSCs in AML as well as CML [28].

Hedgehog (Hh) pathway plays crucial role during embryonic development, tissue regeneration and repair in adults. Zhao et al. (2009) have demonstrated that loss of Smoothened (Smo), an important molecule of the Hh pathway, impairs HSC renewal and results in depletion of CML stem cells [29], although the effect of loss of Hh signaling through conditional deletion of Smo on adult hematopoiesis is still controversial [30,31]. The possible mechanism for the Smo action may be the upregulation of cell fate determinant Numb in the absence of Smo activity, which is responsible for depletion of CML stem cells [32]. Hh pathway activity is required for maintenance of normal and leukemia stem cells of the hematopoietic system.

\section{Kinases}

Src family kinases (SFKs) can be potential biomarkers for BCR-ABL kinase inhibitor resistant CML stem cells. SFKs were reported to be involved in tyrosine kinase inhibitor-resistant CML and elevated SFK activities were observed in patients with advanced disease in blast crisis. In a study of four categories of imatinib- and dasatinibtreated patients (imatinib resistant/dasatinib-responsive; dasatinib-resistant; blast crisis or CML progression and T315I or F317L mutated patient receiving omacetaxine treatment) [33], transcriptional and translational levels of HCK, LYN and another SFK-related gene BTK were elevated in more than $50 \%$ of resistant CML patients. This increase more significantly correlates with disease progression in a large population of CML patients. Interestingly, activation of SFKs expression is not likely caused by BCR-ABL mutation, as four BCR-ABL mutated patients showed concomitant SFK activation similar to that seen in patients expressing a wild-type BCR-ABL [33]. Recently, in BCR-ABL-induced chronic myeloid leukemia animal model, the Blk gene (encoding B-lymphoid kinase, a SRC family kinase) was shown to function as a tumor suppressor in LSCs but it did not affect normal HSCs or hematopoiesis. Blk suppressed LSC function through a pathway involving an upstream regulator, $P a x 5$, and a downstream effector, $p 27$. Inhibition of the $B l k$ pathway accelerated CML development, whereas increased activity 
of the Blk pathway delayed CML development. Blk also suppressed the proliferation of human CML stem cells [22].

\section{Cell adhesion molecules}

Adhesion molecules such as P-selectin (encoded by the Selp gene) are essential for normal hematopoiesis, and their dysregulation has been linked to leukemogenesis [34-36]. Like HSCs, LSCs depend upon their microenvironments for survival and propagation. P-selectin plays a crucial role in Philadelphia chromosome-positive CML [34]. The cells deficient in P-selectin expression can repopulate the bone marrow more efficiently than wild type control cells [36]. This results from an increase in HSC self-renewal rather than alternative possibilities like increased homing velocity or cell cycle defects [36]. Recipients of $B C R-A B L$-transduced bone marrow cells from P-selectin-deficient donors develop more aggressive CML, with increased percentages of LSCs and progenitors [34]. Taken together, P-selectin expression on HSCs and LSCs may have important functional ramifications for both hematopoiesis and leukemogenesis, which is most likely attributable to an intrinsic effect on stem cell self-renewal [36].

Mouse $B C R-A B L$-expressing stem/progenitor cells express a higher level of CD44, which contributes functional E-selectin ligands [37,38]. In a mouse retroviral transplantation model of CML, $B C R-A B L$-transduced progenitors from $C D 44-$ mutant donors are defective in homing to recipient bone marrow, resulting in decreased engraftment and impaired induction of CML. By contrast, CD44-deficient stem cells transduced with empty retrovirus engraft as efficiently as do wild-type HSCs. CD44 is dispensable for induction of acute B-lymphoblastic leukemia by $B C R-A B L$, indicating that $C D 44$ is specifically required for leukemic cells that initiate CML. The requirement for donor CD44 is bypassed by direct intrafemoral injection of $B C R-A B L$-transduced CD44-deficient stem cells or by coexpression of human CD44. Antibody to CD44 attenuates induction of CML in recipients. These results show that $B C R-A B L$-expressing leukemic stem cells depend to a greater extent on CD44 for homing and engraftment than do normal HSCs, and argue that CD44 blockade may be beneficial in autologous transplantation in CML [37]. Loss of CD44 was also reported to be able to alleviate the CML phenotypes in Kras G12D mice and attenuate aberrant GM-CSF signaling in Kras G12D cells [39].

Another cell adhesion molecule MSR1 is a mutifunctional cell surface receptor and downregulated by $B C R-A B L$. This downregulation is partially restored by Alox5 deletion, and that Msr 1 deletion causes acceleration of CML development [40,41]. Moreover, Msr1 deletion markedly increases LSC function through its effects on cell cycle progression and apoptosis. MSR1 was also shown to affect CML development by regulating the PI3K-AKT pathway and $\beta$-Catenin, which suggesting that MSR1 suppresses LSCs and CML development [41]. The lower cell surface expression of MSR1 may also be used to monitor the activity of CML stem cells in patients.

\section{Transcription factor}

Forkhead $\mathbf{O}$ transcription factor3a $($ Foxo3a) was shown to play an essential role in the maintenance of LSCs of CML. Cells with nuclear localization of FOXO3a and decreased AKT phosphorylation are enriched in the LSC population. Serial transplantation of LSCs from Foxo $3 a^{+/+}$and Foxo $3 a^{-/-}$mice shows that the ability of LSCs to cause disease is significantly decreased by Foxo3a deletion. Furthermore, TGF-beta is also shown to be a critical regulator of AKT activation in LSCs and control FOXO3a localization. A combination of TGF-beta inhibition, Foxo3a deficiency and imatinib treatment led to efficient depletion of CML in vivo [42]. The inhibitory effect of FOXO3a on leukemia cells was shown through increasing PI3K/AKT activity in drug-resistant leukemic cells [43]. Recently, BCL6 proto-oncogene was also shown as a critical effector downstream of FoxO in self-renewal signaling of CML stem cells [43].

Hypoxia-inducible factor-1 $\alpha(H i f 1 \alpha)$ is a master transcriptional regulator of the cellular and systemic hypoxia response, and is essential for the maintenance of selfrenewal capacity of normal HSCs and LSC of acute myeloid leukemia [44]. HIF1 $\alpha$ also plays a crucial role in survival maintenance of LSCs of CML. Deletion of Hifl $\alpha$ impairs the propagation of CML through impairing cell-cycle progression and inducing apoptosis of LSCs. Deletion of Hif1 $\alpha$ results in elevated expression of $p 16$ (Ink4a) and $p 19$ (Arf) in LSCs, and knockdown of $p 16$ (Ink4a) and $p 19$ (Arf) rescues the defective colony-forming ability of $\mathrm{Hifl}^{-/-}$LSCs. Compared with normal HSCs, LSCs appear to be more dependent on the HIF1 $\alpha$ pathway [45].

\section{Other genes}

The tumor suppressor gene Pten is also downregulated by $B C R-A B L$ in LSCs of CML mice. By genetic deletion or overexpression of Pten, it was shown to function as a tumor suppressor in LSCs of CML, consistent with the role of PTEN in LSCs of acute myeloid leukemia and progenitor cells of T-ALL progenitors. Functional enhancement of the PTEN pathway provides a therapeutic strategy for targeting LSCs [46].

Bcl6 is a known proto-oncogene that is frequently translocated in diffuse large $\mathrm{B}$ cell lymphoma (DLBCL) [47]. In response to TKI-treatment, BCL6 protein level was upregulated by 90 folds in $B C R-A B L$-positive acute lymphoblastic leukemia cells. BCL6 upregulation upon TKI-treatment leads to transcriptional inactivation of P53 pathway and BCL6-deficient leukemia cells fail to 
inactivate P53 and are particularly sensitive to TKItreatment. $\mathrm{Bcl}^{-1-}$ leukemia cells are poised to undergo cellular senescence and fail to initiate leukemia in serial transplant recipients. A combination of TKI-treatment and a novel BCL6 peptide inhibitor markedly increased survival of NOD/SCID mice xenografted with patientderived BCR-ABL1 ALL cells [48].

PML functions as a tumor suppressor that controls fundamental processes such as apoptosis, cellular proliferation and senescence $[49,50]$. PML was revealed to have an indispensable role in maintaining LIC quiescence. Pml-deficient long-term LSCs become exhausted with time and are incapable of generating CML in transplanted animals [51].

PP2A is a phosphatase regulating many cellular functions and is genetically inactivated in many types of cancer [52]. PP2A activity is suppressed in blast crisis but not chronic phase CML cells through inhibition of BCRABL. Restoration of PP2A activity inhibits BCR-ABL expression and activity, hence impairing wild-type and T315I BCR-ABL leukemogenesis. In addition, pharmacologic enhancement of PP2A may represent a possible therapeutic strategy for blast crisis and imatinib-resistant CML [53].

\section{Summary}

Although our current knowledge of the biology and therapy of CML LSCs is still limited, the identification of novel gene signatures, such as HSC development related genes, cell metabolism regulators, kinases, cell adhesion molecules and transcription factors (Table 1), provide the new opportunities for not only monitoring the proliferation of CML stem cells, but also developing promising anti-stem cell therapies for curing CML. Future clinical trials for testing those gene signatures in CML patients will determine whether novel $B C R-A B L$ kinase inhibitors or other combinational therapies are effective in killing CML stem cells and curing the patients.

\section{Competing interests}

The authors declare that they have no competing interests.

\section{Authors' contributions \\ YC and SL wrote the manuscript. All authors read and approved the final manuscript.}

\section{Author details \\ 'Department of Oncology, Novartis Institutes for Biomedical Research, 250 Mass Ave, Cambridge, MA 02139, USA. ${ }^{2}$ Department of Medicine, Division of Hematology/Oncology, University of Massachusetts Medical School, 364 Plantation Street, Worcester, MA 01605, USA. ${ }^{3}$ Department of Medicine, University of Massachusetts Medical School, 364 Plantation Street, Worcester, MA 01605, USA.}

Received: 18 February 2013 Accepted: 3 June 2013

Published: 6 June 2013

\section{References}

1. Druker BJ, Sawyers CL, Kantarjian H, Resta DJ, Reese SF, Ford JM, Capdeville $R$, Talpaz M: Activity of a specific inhibitor of the BCR-ABL tyrosine kinase in the blast crisis of chronic myeloid leukemia and acute lymphoblastic leukemia with the Philadelphia chromosome. N Eng J Med 2001, 344:1038-1042.

2. Druker BJ, Talpaz M, Resta DJ, Peng B, Buchdunger E, Ford JM, Lydon NB, Kantarijian H, Capdeville R, Ohno-Jones S, Sawyers CL: Efficacy and safety of a specific inhibitor of the BCR-ABL tyrosine kinase in chronic myeloid leukemia. N Eng J Med 2001, 344:1031-1037.

3. Druker BJ, Guilhot F, O'Brien SG, Gathmann I, Kantarjian H, Gattermann N, Deininger MW, Silver RT, Goldman JM, Stone RM, et al: Five-year follow-up of patients receiving imatinib for chronic myeloid leukemia. N Eng J Med 2006, 355:2408-2417.

4. Holyoake $T$, Jiang $X$, Eaves $C$, Eaves $A$ : Isolation of a highly quiescent subpopulation of primitive leukemic cells in chronic myeloid leukemia. Blood 1999, 94:2056-2064.

5. Graham SM, Jorgensen HG, Allan E, Pearson C, Alcorn MJ, Richmond L, Holyoake TL: Primitive, quiescent, Philadelphia-positive stem cells from patients with chronic myeloid leukemia are insensitive to STI571 in vitro. Blood 2002, 99:319-325.

6. Rousselot P, Huguet F, Rea D, Legros L, Cayuela JM, Maarek O, Blanchet O, Marit G, Gluckman E, Reiffers J, et al: Imatinib mesylate discontinuation in patients with chronic myelogenous leukemia in complete molecular remission for more than 2 years. Blood 2007, 109:58-60.

7. Chen Y, Peng C, Sullivan C, Li D, Li S: Critical molecular pathways in cancer stem cells of chronic myeloid leukemia. Leukemia 2010, 24:1545-1554.

8. Al-Hajj M, Wicha MS, Benito-Hernandez A, Morrison SJ, Clarke MF: Prospective identification of tumorigenic breast cancer cells. Proc Nat/ Acad Sci USA 2003, 100:3983-3988.

9. Jordan CT, Guzman ML, Noble M: Cancer stem cells. N Eng J Med 2006, 355:1253-1261.

10. Pardal R, Clarke MF, Morrison SJ: Applying the principles of stem-cell biology to cancer. Nat Rev Cancer 2003, 3:895-902.

11. Reya T, Morrison SJ, Clarke MF, Weissman IL: Stem cells, cancer, and cancer stem cells. Nature 2001, 414:105-111.

12. Rossi DJ, Jamieson CH, Weissman IL: Stems cells and the pathways to aging and cancer. Cell 2008, 132:681-696.

13. Park CY, Tseng D, Weissman IL: Cancer stem cell-directed therapies: recent data from the laboratory and clinic. Mol Ther 2009, 17:219-230.

14. Li S, Ilaria RL Jr, Million RP, Daley GQ, Van Etten RA: The P190, P210, and P230 forms of the BCR/ABL oncogene induce a similar chronic myeloid leukemia-like syndrome in mice but have different lymphoid leukemogenic activity. J Exp Med 1999, 189:1399-1412.

15. Hu Y, Swerdlow S, Duffy TM, Weinmann R, Lee FY, Li S: Targeting multiple kinase pathways in leukemic progenitors and stem cells is essential for improved treatment of $\mathrm{Ph}+$ leukemia in mice. Proc Natl Acad Sci USA 2006, 103:16870-16875.

16. Druker BJ, Sawyers CL, Capdeville R, Ford JM, Baccarani M, Goldman JM: Chronic myelogenous leukemia. Hematology Am Soc Hematol Educ Program 2001, 2001:87-112.

17. Bhatia R, Holtz M, Niu N, Gray R, Snyder DS, Sawyers CL, Arber DA, Slovak ML, Forman SJ: Persistence of malignant hematopoietic progenitors in chronic myelogenous leukemia patients in complete cytogenetic remission following imatinib mesylate treatment. Blood 2003, 101:4701-4707.

18. Corbin AS, Agarwal A, Loriaux M, Cortes J, Deininger MW, Druker BJ: Human chronic myeloid leukemia stem cells are insensitive to imatinib despite inhibition of BCR-ABL activity. J Clin Invest 2011, 121:396-409.

19. Peters-Golden M, Henderson WR Jr: Leukotrienes. N Eng J Med 2007, 357:1841-1854.

20. Chen $Y$, Hu Y, Zhang H, Peng C, Li S: Loss of the Alox5 gene impairs leukemia stem cells and prevents chronic myeloid leukemia. Nat Genet 2009, 41:783-792.

21. Scaglia N, Igal RA: Stearoyl-CoA desaturase is involved in the control of proliferation, anchorage-independent growth, and survival in human transformed cells. J Biol Chem 2005, 280:25339-25349.

22. Zhang H, Peng C, Hu Y, Li H, Sheng Z, Chen Y, Sullivan C, Cerny J, Hutchinson L, Higgins $A$, et al: The Blk pathway functions as a tumor suppressor in chronic myeloid leukemia stem cells. Nat Genet 2012, 44:861-871.

23. Ikeda S, Kishida S, Yamamoto H, Murai H, Koyama S, Kikuchi A: Axin, a negative regulator of the Wnt signaling pathway, forms a complex with 
GSK-3beta and beta-catenin and promotes GSK-3beta-dependent phosphorylation of beta-catenin. EMBO J 1998, 17:1371-1384.

24. Jamieson CH, Ailles LE, Dylla SJ, Muijtjens M, Jones C, Zehnder JL, Gotlib J, Li K, Manz MG, Keating A, et al: Granulocyte-macrophage progenitors as candidate leukemic stem cells in blast-crisis CML. N Eng J Med 2004 351:657-667.

25. Correa S, Binato R, Du Rocher B, Castelo-Branco MT, Pizzatti L, Abdelhay E: Wnt/beta-catenin pathway regulates $A B C B 1$ transcription in chronic myeloid leukemia. BMC Cancer 2012, 12:303

26. Gregory MA, Phang TL, Neviani $P$, Alvarez-Calderon F, Eide CA, O'Hare T, Zaberezhnyy V, Williams RT, Druker BJ, Perrotti D, Degregori J: Wnt/Ca2+/ NFAT signaling maintains survival of $\mathrm{Ph}+$ leukemia cells upon inhibition of Bcr-Abl. Cancer Cell 2010, 18:74-87.

27. Zhang B, Li M, McDonald T, Holyoake TL, Moon RT, Campana D, Shultz L, Bhatia R: Microenvironmental protection of CML stem and progenitor cells from tyrosine kinase inhibitors through $\mathrm{N}$-cadherin and Wnt-betacatenin signaling. Blood 2013, 121:1824-1838.

28. Wang $Y$, Krivtsov AV, Sinha AU, North TE, Goessling W, Feng Z, Zon LI, Armstrong SA: The Wnt/beta-catenin pathway is required for the development of leukemia stem cells in AML. Science 2010, 327:1650-1653.

29. Dierks C, Beigi R, Guo GR, Zirlik K, Stegert MR, Manley P, Trussell C, SchmittGraeff A, Landwerlin K, Veelken H, Warmuth M: Expansion of Bcr-Ablpositive leukemic stem cells is dependent on Hedgehog pathway activation. Cancer Cell 2008, 14:238-249.

30. Hofmann I, Stover EH, Cullen DE, Mao J, Morgan K, Lee BH, Kharas MG, Miller PG, Cornejo MG, Okabe R, et al: Hedgehog signaling is dispensable for adult murine hematopoietic stem cell function and hematopoiesis. Cell Stem Cell 2009, 4:559-567.

31. Gao J, Graves S, Koch U, Liu S, Jankovic V, Buonamici S, El Andaloussi A, Nimer SD, Kee BL, Taichman R, et al: Hedgehog signaling is dispensable for adult hematopoietic stem cell function. Cell Stem Cell 2009, 4:548-558.

32. Zhao C, Chen A, Jamieson CH, Fereshteh M, Abrahamsson A, Blum J, Kwon HY, Kim J, Chute JP, Rizzieri D, et al: Hedgehog signalling is essential for maintenance of cancer stem cells in myeloid leukaemia. Nature 2009, 458:776-779.

33. Hayette S, Chabane K, Michallet M, Michallat E, Cony-Makhoul P, Salesse S, Maguer-Satta V, Magaud JP, Nicolini FE: Longitudinal studies of SRC family kinases in imatinib- and dasatinib-resistant chronic myelogenous leukemia patients. Leuk Res 2011, 35:38-43.

34. Pelletier SD, Hong DS, Hu Y, Liu Y, Li S: Lack of the adhesion molecules Pselectin and intercellular adhesion molecule-1 accelerate the development of $\mathrm{BCR} / \mathrm{ABL}$-induced chronic myeloid leukemia-like myeloproliferative disease in mice. Blood 2004, 104:2163-2171.

35. Rossi DJ, Bryder D, Zahn JM, Ahlenius H, Sonu R, Wagers AJ, Weissman IL: Cell intrinsic alterations underlie hematopoietic stem cell aging. Proc Natl Acad Sci USA 2005, 102:9194-9199.

36. Sullivan $C$, Chen Y, Shan Y, Hu Y, Peng C, Zhang H, Kong L, Li S: Functional ramifications for the loss of $\mathrm{P}$-selectin expression on hematopoietic and leukemic stem cells. PLoS One 2011, 6:e26246.

37. Krause DS, Lazarides K, von Andrian UH, Van Etten RA: Requirement for CD44 in homing and engraftment of BCR-ABL-expressing leukemic stem cells. Nat Med 2006, 12:1175-1180.

38. Dimitroff CJ, Lee JY, Rafii S, Fuhlbrigge RC, Sackstein R: CD44 is a major Eselectin ligand on human hematopoietic progenitor cells. J Cell BiO/ 2001 , 153:1277-1286.

39. Du J, Liu Y, Meline B, Kong G, Tan LX, Lo JC, Wang J, Ranheim E, Zhang L, Chang Yl, et al: Loss of CD44 attenuates aberrant GM-CSF signaling in Kras G12D hematopoietic progenitor/precursor cells and prolongs the survival of diseased animals. Leukemia 2013, 27:754-757.

40. Chen Y, Wang X, Ben J, Yue S, Bai H, Guan X, Bai X, Jiang L, Ji Y, Fan L, Chen $\mathrm{Q}$ : The di-leucine motif contributes to class a scavenger receptormediated internalization of acetylated lipoproteins. Arterioscler Thromb Vasc Biol 2006, 26:1317-1322

41. Chen Y, Sullivan C, Peng C, Shan Y, Hu Y, Li D, Li S: A tumor suppressor function of the Msr1 gene in leukemia stem cells of chronic myeloid leukemia. Blood 2011, 118:390-400

42. Naka K, Hoshii T, Muraguchi T, Tadokoro $Y$, Ooshio $T$, Kondo $Y$, Nakao S, Motoyama N, Hirao A: TGF-beta-FOXO signalling maintains leukaemia-initiating cells in chronic myeloid leukaemia. Nature 2010, 463:676-680.
43. Hui RC, Gomes AR, Constantinidou D, Costa JR, Karadedou CT, de Mattos Fernandez S, Wymann MP, Brosens JJ, Schulze A, Lam EW: The forkhead transcription factor FOXO3a increases phosphoinositide-3 kinase/Akt activity in drug-resistant leukemic cells through induction of PIK3CA expression. Mol Cell Biol 2008, 28:5886-5898.

44. Wang Y, Liu Y, Malek SN, Zheng P: Targeting HIF1alpha eliminates cance stem cells in hematological malignancies. Cell Stem Cell 2011, 8:399-411.

45. Zhang $\mathrm{H}, \mathrm{Li} \mathrm{H}, \mathrm{Xi} \mathrm{HS}, \mathrm{Li} \mathrm{S}$ : HIF1alpha is required for survival maintenance of chronic myeloid leukemia stem cells. Blood 2012, 119:2595-2607.

46. Peng $C$, Chen $Y$, Yang Z, Zhang H, Osterby L, Rosmarin AG, Li S: PTEN is a tumor suppressor in CML stem cells and BCR-ABL-induced leukemias in mice. Blood 2010, 115:626-635

47. Saito M, Gao J, Basso K, Kitagawa Y, Smith PM, Bhagat G, Pernis A, Pasqualucci L, Dalla-Favera R: A signaling pathway mediating downregulation of BCL6 in germinal center B cells is blocked by BCL6 gene alterations in B cell lymphoma. Cancer Cell 2007, 12:280-292.

48. Duy C, Hurtz C, Shojaee S, Cerchietti L, Geng H, Swaminathan S, Klemm L, Kweon SM, Nahar R, Braig M, et al: BCL6 enables Ph+ acute lymphoblastic leukaemia cells to survive BCR-ABL1 kinase inhibition. Nature 2011, 473:384-388.

49. Salomoni P, Pandolfi PP: The role of PML in tumor suppression. Cell 2002, 108:165-170.

50. Wang ZG, Ruggero D, Ronchetti S, Zhong S, Gaboli M, Rivi R, Pandolfi PP: PML is essential for multiple apoptotic pathways. Nat Genet 1998, 20:266-272.

51. Ito K, Bernardi R, Morotti A, Matsuoka S, Saglio G, Ikeda Y, Rosenblatt J, Avigan DE, Teruya-Feldstein J, Pandolfi PP: PML targeting eradicates quiescent leukaemia-initiating cells. Nature 2008, 453:1072-1078.

52. Janssens V, Goris J: Protein phosphatase $2 A$ : a highly regulated family of serine/threonine phosphatases implicated in cell growth and signalling. Biochem J 2001, 353:417-439.

53. Neviani P, Santhanam R, Trotta R, Notari M, Blaser BW, Liu S, Mao H, Chang JS, Galietta A, Uttam A, et al: The tumor suppressor PP2A is functionally inactivated in blast crisis CML through the inhibitory activity of the BCR/ ABL-regulated SET protein. Cancer Cell 2005, 8:355-368.

doi:10.1186/2050-7771-1-21

Cite this article as: Chen and Li: Molecular signatures of chronic myeloid leukemia stem cells. Biomarker Research 2013 1:21.

\section{Submit your next manuscript to BioMed Central and take full advantage of:}

- Convenient online submission

- Thorough peer review

- No space constraints or color figure charges

- Immediate publication on acceptance

- Inclusion in PubMed, CAS, Scopus and Google Scholar

- Research which is freely available for redistribution

Submit your manuscript at www.biomedcentral.com/submit
C) Biomed Central 